\title{
Dual role of macrophage migration inhibitory factor (MIF) in human breast cancer
}

\author{
Eva Verjans ${ }^{1}$, Erik Noetzel ${ }^{2}$, Nuran Bektas² ${ }^{2}$ Anke K Schütz1 ${ }^{1}$ Hongqi Lue ${ }^{1}$, \\ Birgitt Lennartz ${ }^{1}$, Arndt Hartmann ${ }^{3}$, Edgar Dahl ${ }^{2}$ and Jürgen Bernhagen*1
}

\author{
Address: ${ }^{1}$ Department of Biochemistry and Molecular Cell Biology, RWTH Aachen University Hospital, Aachen, Germany, ${ }^{2}$ Molecular Oncology \\ Group, Institute of Pathology, RWTH Aachen University Hospital, Aachen, Germany and ${ }^{3}$ Institute of Pathology, University of Erlangen, Erlangen, \\ Germany \\ Email: Eva Verjans - eva.verjans@rwth-aachen.de; Erik Noetzel - enoetzel@ukaachen.de; Nuran Bektas - nbektas@ukaachen.de; \\ Anke K Schütz - anke.schuetz@gmx.de; Hongqi Lue - hlue@ukaachen.de; Birgitt Lennartz - blennartz@ukaachen.de; \\ Arndt Hartmann - arndt.hartmann@uk-erlangen.de; Edgar Dahl - edahl@ukaachen.de; Jürgen Bernhagen* - jbernhagen@ukaachen.de \\ * Corresponding author
}

Published: 14 July 2009

BMC Cancer 2009, 9:230 doi:10.1 186/147/-2407-9-230
Received: I January 2009

Accepted: I4 July 2009

This article is available from: http://www.biomedcentral.com/I47/-2407/9/230

(C) 2009 Verjans et al; licensee BioMed Central Ltd.

This is an Open Access article distributed under the terms of the Creative Commons Attribution License (http://creativecommons.org/licenses/by/2.0), which permits unrestricted use, distribution, and reproduction in any medium, provided the original work is properly cited.

\begin{abstract}
Background: Macrophage migration inhibitory factor (MIF) is a pleiotropic cytokine and mediator of acute and chronic inflammatory diseases. MIF is overexpressed in various tumours and has been suggested as a molecular link between chronic inflammation and cancer. MIF overexpression is observed in breast cancer but its causal role in the development of this tumour entity is unclear.

Methods: MIF levels in breast cancer cell lines were determined by ELISA and Western blot. CD74 was measured by Western blot, fluorescence microscopy and flow cytometry. Cell proliferation was studied by BrdU incorporation, cell adhesion by Matrigel adhesion assay, and cell invasion by migration assay through Matrigel-coated filters using the Transwell system. MIF expression in primary human breast cancers was measured by tissue microarray and a semi-quantitative immunoreactivity score (IRS) and comparison with histopathological parameters and patient outcome data.

Results: MIF was abundantly expressed in the non-invasive breast cancer cell lines MDA-MB-468 and ZR75-I, but not in invasive MDA-MB-23I cells, which in turn expressed higher levels of the MIF-receptor CD74. Stimulation with exogenous MIF led to a dramatic upregulation of MIF secretion (50-fold) in MDAMB-23 I cells. Autocrine MIF promoted tumour cell proliferation, as indicated by blockade of MIF or CD74 in MDA-MB-23I and MDA-MB-468, and MDA-MB-23I invasiveness was enhanced by exogenous MIF. We correlated the expression of MIF with histopathological parameters and patient outcome data, using a tissue microarray of 175 primary invasive breast cancers and 35 normal control tissues. MIF was upregulated in breast cancer versus normal tissue (median IRS $=8$ versus 6 ). MIF expression showed positive correlations with progesterone $(p=0.006)$ and estrogen $(p=0.028)$ receptor expression, markers of a favourable prognosis and a negative correlation to tumour size $(p=0.007)$. In line with these data, disease-specific overall (OS) as well as recurrence-free (RFS) survival was significantly improved in breast cancer patients with abundant cytosolic MIF expression compared to MIF low expressers (5-year OS $=67 \%$ versus $50 \%, p=0.0019 ; 5$-year RFS $=52 \%$ versus $36 \%, p=0.0327$ ).
\end{abstract}

Conclusion: We conclude that intracellular expression of MIF in breast cancer cells is beneficial, whereas extracellular MIF may play a pro-oncogenic role in promoting breast cancer cell-stroma interactions. 


\section{Background}

Macrophage migration inhibitory factor (MIF) is a pleiotropic cytokine and upstream regulator of the host immunity that promotes cellular inflammatory responses such as mitogen-activated protein kinase (MAPK) signalling, tumour necrosis factor- $\alpha$ (TNF- $\alpha$ ) secretion or cyclooxygenase-2 (COX-2) activity. Owing to its inflammatory activities, MIF is a pivotal mediator of acute and chronic inflammatory diseases including septic shock, rheumatoid arthritis, and atherosclerosis [1-4]. MIF is not only secreted by immune cells, but also by parenchymal and tumour cells upon inflammatory and stress stimulation [1]. Sharing an architectural 3D similarity with the atherogenic and angiogenic chemokine interleukin-8 (IL-8)/ CXCL8, MIF was found to function as a non-cognate ligand of CXCR2 and as chemokine-like function (CLF) chemokine. Inflammatory leukocyte recruitment is dependent on MIF-CXCR2 and MIF-CXCR4 interactions [5]. As observed for CLF chemokines, MIF action is not limited to the extracellular space, but also occurs intracellularly. MIF is found in the cytosol of various cell types, where it contributes to cell survival, cell cycle and homeostasis control. Intracellular MIF activities are linked to cJun activation domain binding protein-1 (JAB1), the tumour suppressor protein $\mathrm{p} 53$, and the thiolprotein oxidoreductase (TPOR) activity of MIF [1,6-8].

MIF has been implicated in cancerogenesis already as early as in 1999, when Mitchell and colleagues found that it mimics the action of oncogenic RAS protein by inducing sustained ERK1/2 signalling [9]. Meanwhile, it has been appreciated that MIF constitutes an important link between chronic inflammation and cancer. Of note, MIF levels are markedly elevated in numerous tumour entities such as prostate tumours, breast cancer, or colon carcinomas [10-12]. Recombinant MIF (rMIF) promotes cell proliferation and migration and blockade of MIF by antibodies or gene deletion leads to reduced proliferation and inhibition of tumour growth and angiogenesis [1318]. Pro-tumourigenic activities of MIF involve the MIF receptor CD74 and stimulation of the phosphoinositide3-kinase (PI3K)/AKT/SRC signal transduction cascade [9,19-21]. Moreover, MIF inhibits p53-dependent gene expression and suppresses apoptosis. Secretion of MIF by tumour cells has been proposed to enhance tumour cell proliferation by autocrine amplification as known for other growth factors expressed by cancer cells $[6,18,22,23]$. CD74 is expressed on various cancer cells, i.e. prostate cancer cells, B lymphomas, or gastric carcinomas [24-26], but its expression in breast cancer has not been studied. Of note, binding of MIF to CD74 leads to the recruitment of the hyaluronate receptor CD44 and CD74/CD44 complexes have been implicated in protumourigenic MIF signalling processes $[27,28]$. Although its precise role has remained unclear, CD44 has been amply associated with breast cancer pathogenesis [29,30].

MIF is overexpressed in various breast cancer cell lines and human breast cancer tissue but its functional role in the pathogenesis of this tumour entity is poorly understood $[12,21,31]$. Given that intracellular MIF has been reported to have a beneficial role in improving cell homeostasis and that secreted and extracellular MIF has various protumourigenic and pro-inflammatory effects, it is conceivable that the clinicopathological role of MIF in breast cancer is complex and may vary with tumour stage and type. Hagemann et al. investigated MIF induction in breast tumour-stroma interactions. MIF was identified as a major gene product upregulated in breast cancer cells upon coculture with macrophages. TNF $\alpha$-triggered tumour cellderived MIF led to increased macrophage metalloproteinase production rates and facilitated tumour cell invasion [32].

To clarify the causal involvement of MIF in breast cancer, we investigated the role of MIF and its receptor CD74 in cytokine production, proliferation, and invasion of invasive versus non-invasive breast cancer cells. Moreover, we undertook a comprehensive study correlating MIF expression levels in 175 breast cancer specimens with clinicopathological parameters and patient outcome data including overall (OS) and recurrence-free survival (RFS).

\section{Methods}

\section{Breast cancer tissue microarray (TMA)}

A TMA was constructed as described previously [33] and contained 289 non-selected formalin-fixed, paraffinembedded primary breast cancers (stage I-IIIC) together with matched normal breast tissue. All patients gave informed consent for retention and analysis of their tissue for research purposes and the study was approved by the Ethical Committee of the University of Regensburg. An experienced surgical pathologist (A.H.) evaluated H\&Estained slides of all specimens before construction of the TMA to identify representative tumour areas and to reevaluate tumour grading. Clinical follow-up, provided by the Central Tumor Registry Regensburg, Germany, was available for all breast cancer patients with a median follow-up period of 79 months (0-148 months). Clinicopathologic parameters of breast cancer cases included in the TMA are summarized in a supplementary table (see Additional File 1).

\section{Cells and reagents}

Cell culture reagents were purchased from Invitrogen. Neutralising anti-CD74 monoclonal antibodies (mAbs) (sc-5438) were from Santa Cruz and FITC-labelled antiCD74 was from Biomedia. The anti-MIF mAb NIH/III.D9 was from the Bucala lab (New Haven, USA) and control 
IgG was of the IgG1 subtype [5]. Anti-actin C4 mouse $\mathrm{mAb}$ was from MP Biomedicals, sheep anti-mouse $\left(\mathrm{Fab}^{\prime}\right)_{2}$ from GE Healthcare and FITC-labelled anti-mouse antibody from Dianova. Polyclonal anti-MIF antibody (Ka565) and rMIF were generated as described [5].

The normal breast epithelial line MCF-12A, non-invasive breast cancer cell lines MDA-MB-468 (infiltrating adenocarcinoma) and ZR-75-1 (infiltrating ductal carcinoma), and highly invasive MDA-MB-231 cells (invasive ductal carcinoma) were cultured as described [21].

\section{Cell lysis and Western blotting analysis}

Cell lysates for Western blotting were prepared from 100.000 cells and subjected to NuPAGE ${ }^{\circledR}$ electrophoresis/ Western blotting as described [21]. MIF and CD74 were detected by anti-CD74 (sc-5438; Santa Cruz) and antiMIF (Ka565) primary antibodies, respectively; anti-actin (C4; 1:500 dilution) was used for standardisation. Following treatment with HRP-conjugated secondary Ab, bands were quantified by ECL chemiluminescence as described [21]. Quantifications of blots are representative of 3-5 independent experiments.

\section{Stimulations with rMIF and MIF ELISA}

Cells were incubated at 100,000 cells per well in medium containing $10 \%$ FCS for $24 \mathrm{~h}$ at $37^{\circ} \mathrm{C}$. Medium was adjusted to low serum (0.5\% FCS) and cells cultured for 48 h. $150 \mathrm{ng} / \mathrm{ml}$ of rMIF were added to cells $10 \mathrm{~min}$ to 48 $\mathrm{h}$ before the end of the incubation. Control incubations were performed for each time interval. Supernatants were analysed for MIF by commercial human MIF ELISA (R\&D Systems). For each time interval, 3-6 independent experiments were performed and each sample was analysed by triplicate ELISA measurements.

\section{Fluorescence microscopy}

Living cells were seeded on cover slips in 6-well plates. Washed cells were incubated in PBS with FITC-labelled anti-CD74 Ab for $1 \mathrm{~h}$. Control cells were treated with an irrelevant FITC-labelled antibody. After fixation, cells were analysed by fluorescence microscopy and 10 pictures evaluated for each sample.

\section{Proliferation assay}

8,000 cells were plated and proliferation measured over 24-72 h followed by a $6 \mathrm{~h}$ incubation with BrdU using a commercial BrdU proliferation kit from Roche Diagnostics. Antibodies for neutralisation experiments and isotype control IgG $(58 \mu \mathrm{g} / \mathrm{ml})$, and/or rMIF at different concentrations $(0,10,50$, and $150 \mathrm{ng} / \mathrm{ml})$ were added at the beginning of the incubation period.

\section{Matrigel invasion assay}

Matrigel invasion assay was conducted in 24-well plates applying the Transwell device containing microporous 8 $\mu \mathrm{m}$ membranes (Corning, USA). Membranes were coated with Matrigel (500 ng/ml) and MDA-MB-231 cells seeded in the upper chamber containing basal medium with $0.5 \%$ BSA. rMIF was added to the lower chamber at final concentrations between 0 and $100 \mathrm{ng} / \mathrm{ml}$. 10\% FCS served as positive chemoattractant control. Migration/invasion was followed for $72 \mathrm{~h}$. Transwell inserts were transferred to a new plate and cells adhering to the lower surface were stained with $8 \mathrm{mM}$ calcein (Calbiochem). The total number of invading cells was acquired in six representative fields using fluorescence microscopy (10 × magnification).

\section{Real-time PCR}

Total RNA processing and real-time PCR were performed as described [34]. PCR primer sequences: MIF-F312 (5'AGAACCGCTCCTACAGCAAG 3') and MIF-R432 (5' GAGTTGTTCCAGCCCACATT 3'). Intensity was normalised to GAPDH. PCR conditions were: $95^{\circ} \mathrm{C}$ for $5 \mathrm{~min} ; 40$ cycles of $95^{\circ} \mathrm{C}$ for $20 \mathrm{~s}, 61^{\circ} \mathrm{C}$ for $61 \mathrm{~s}$, and $72^{\circ} \mathrm{C}$ for $12 \mathrm{~s}$; $60 \mathrm{~s}$ at $72^{\circ} \mathrm{C}$. Relative quantification of gene expression was performed using the comparative CT ( $\Delta \Delta$ CT) method.

\section{Immunohistochemistry}

Three $\mu \mathrm{m}$ micrometer sections were prepared and immunohistochemically stained as described elsewhere [34]. Tissue sections were stained with an anti-human MIF antibody (MAB289, R\&D Systems) at a 1:400 dilution.

\section{Statistical analyses}

In vitro assays: Results are expressed as means \pm SD. Graphs were created with Origin Pro 7.0 (Origin Corp.) and data analysed with Student's t-test.

TMA: MIF protein expression was quantified using the immunoreactive score of Remmele and Stegner which consists of the mathematical product of quantity (score 04) and intensity (score 1-3) of protein staining [35]. Statistical analyses were performed using SPSS version 14.0 (SPSS). Two-sided Tarone-Ware tests/Fisher's exact tests were performed to correlate RFS and OS with MIF expression and clinicopathological parameters. Multivariate proportional hazard Cox regression was performed to test for independent prognostic relevance. The limit for reverse selection procedures was $p=0.2$. The proportionality assumption for all variables was assessed with lognegative-log survival distribution functions.

Differences were considered significant at $\mathrm{p}$ values $<0.05$. 


\section{Results \\ Differential expression of MIF and CD74 in invasive versus non-invasive breast cancer cells}

We first applied quantitative PCR (Figure 1a) and Western blotting (Figure $1 \mathrm{~b}-\mathrm{c}$ ) to study the mRNA and protein expression levels of MIF, respectively, in various invasive and non-invasive ductal breast cancer cell lines in comparison to normal epithelial cells. Non-invasive MDAMB-468 and ZR-75-1 cells showed an upregulation of MIF compared to benign epithelial MCF-12A cells, both at the mRNA and protein level, confirming earlier observations [21]. Surprisingly, invasive MDA-MB-231 breast cancer cells exhibited significantly lower MIF mRNA and protein levels when compared with the non-invasive cells or MCF$12 \mathrm{~A}$. Thus, MIF de novo synthesis and intracellular protein storage differ between normal epithelial and breast cancer cells and highly invasive cells produce low concentrations of this cytokine.

Next, we measured expression of the MIF receptor CD74 by Western blotting, immunocytochemistry (IHC), and flow cytometry (Figure 2). Generally, CD74 expression was not very prominent in the cells tested. Western blotting and IHC analysis showed marked expression of CD74 in MDA-MB-231, but expression was weak to absent in MDA-MB468 and MCF-12A, as judged by these methods, respectively. IHC indicated that $\mathrm{CD} 74$ expression in MDA-MB-231 was mostly intracellular, an observation that was in line with previous knowledge on the cellular distribution of CD74/Ii. Flow cytometry analysis confirmed that in MDA-MB-231 cells, some portion of CD74 was localised on the cell surface (Figure 2c). Interestingly, this method also revealed surface expression of CD74 on MDA-MB-468 and MCF-12A cells, which was comparable to that on MDA-MB-231 cells. Overall, invasive MDA-MB231 cells exhibited the highest levels of CD74, which were mostly intracellular. Thus, CD74 appears to be primarily expressed in invasive breast cancer cells, indicating that such tumour cells may be prone to stimulation with MIF.

\section{MIF secretion by breast cancer cells is dramatically upregulated by exogenous MIF}

Upon inflammatory stimulation, tumour cells secrete growth factors and cytokines, which amplify neoplastic tumour cell transformation and participate in tumourstroma interactions and activation of tumour-associated macrophages (TAMs). MIF is produced and secreted by both monocytes/macrophages and tumour cells and has pro-tumourigenic activities in vitro. To begin to study potential amplifying effects of exogenous MIF, i.e. MIF released in the tumour microenvironment by TAMs or breast cancer cells themselves, we examined the secretion of MIF in unstimulated breast cancer cells and in those exposed to exogenous recombinant MIF (rMIF). First, spontaneously secreted MIF levels were measured in unstimulated MCF-12A, MDA-MB-468, and MDA-MB231 cells by ELISA. In both tumour cell lines, accumulated MIF concentrations in the supernatants reached appreciable concentrations (Figure 3a), whereas no constitutive MIF release was observed in MCF-12A. The MIF secretion rate in MDA-MB-468 was 4-6-fold higher than in MDAMB-231, reaching $>35 \mathrm{ng} / \mathrm{ml}$ after $48 \mathrm{~h}$. Thus, in cycling breast cancer cells, MIF production and secretion rates exceeded re-endocytosis and degradation.

We next studied the effect of rMIF on the secretion rate of endogenous MIF. Notably, treatment with $150 \mathrm{ng} / \mathrm{ml}$ rMIF not only stimulated endogenous MIF secretion constituting an autocrine loop, but led to a remarkable upregulation of MIF secretion in both non-invasive and invasive tumour cells (Figure $3 \mathrm{~b}$ ). MIF levels were way in excess over the added $150 \mathrm{ng} / \mathrm{ml}$ and significantly increased over the release seen in MCF-12A. The most dramatic effect was seen in MDA-MB-468 stimulated with rMIF for $20 \mathrm{~min}$, where secreted MIF levels reached up to $1000 \mathrm{ng} / \mathrm{ml}$, but also in MDA-MB-231, in which MIF secretion reached $500 \mathrm{ng} / \mathrm{ml}$. Upregulation of MIF secretion by MIF was specific as boiled rMIF and a control buffer had no effect (data not shown). Whereas in MDAMB-468, secreted MIF peaked at $20 \mathrm{~min}$ and then declined, secretion in MDA-MB-231 exhibited a broad plateau between $20 \mathrm{~min}$ and $48 \mathrm{~h}$ of stimulation with rMIF (Figure 3b). We calculated the relative upregulation factors of MIF secretion (ratio of rMIF-induced MIF secretion over basal MIF secretion) in both breast cancer cell types. This analysis demonstrated that the invasive cells exhibited dramatic relative upregulation factors of up to 55-fold (Figure 3c), whereas relative upregulation in MDA-MB-468 was less than 10-fold and even lower than in normal breast epithelial cells. rMIF-triggered secretion of endogenous breast cancer cell-MIF is likely to encompass both a burst of preformed MIF release at 10-20 min and de novo synthesized MIF, appearing $4 \mathrm{~h}$ after inflammatory stimulation with rMIF. Thus, MIF secretion from breast cancer cells could be strongly influenced by auto- or paracrine MIF effects in the tumour-stroma microenvironment.

\section{MIF supports the proliferation rate of breast cancer cells} We next compared unstimulated proliferation rates in two breast cancer cell lines and MCF-12A by BrdU incorporation assay. Invasive MDA-MB-231 cells showed the highest baseline proliferation rate ( 7.8 -fold), while MDAMB-468 proliferated 2.1-fold stronger than MCF-12A cells (Figure 4a). We then stimulated the cells with different rMIF concentrations, ranging from $0-150 \mathrm{ng} / \mathrm{ml}$. rMIF enhanced the proliferation of both tumour cell lines and also that of MCF-12A (Figure 4b). Peak stimulation was obtained with $10 \mathrm{ng} / \mathrm{ml} \mathrm{rMIF}$, a typical concentration measured in (patho)physiological fluids [2], but overall, 
a

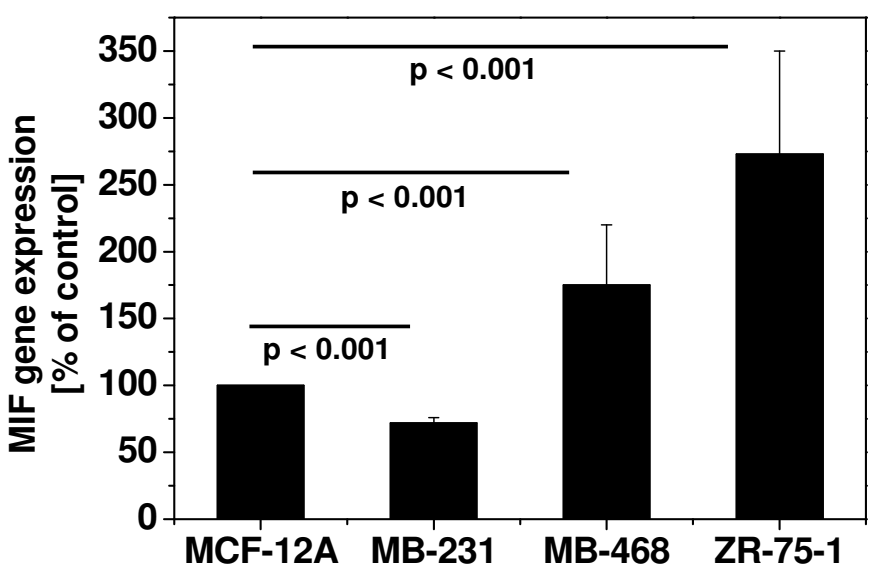

b

MCF-12A MB-231 MB-468 ZR-75-1

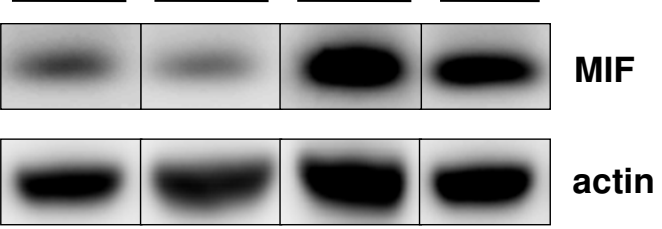

C

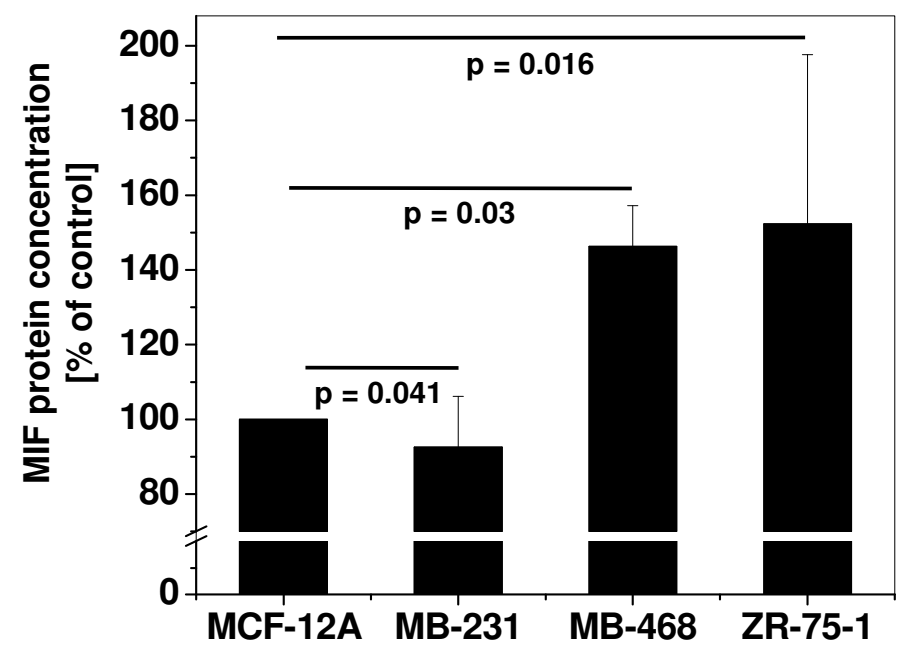

Figure I

MIF is overexpressed in breast cancer cells, but differs in its expression between invasive versus non-invasive cells. (a) Comparison of MIF mRNA levels in non-tumorous MCF-I2A cells with the invasive MDA-MB-23 I and non-invasive MDA-MB-468 and ZR-75-I breast cancer cell lines. mRNA of non-stimulated cells was isolated, transcribed to cDNA, and MIF gene expression measured by real-time PCR. Gene expression levels are shown relative to the expression level in MCF-I2A. Data are means of two determinations and are representative of two independent experiments. (b) As in (a) but comparison of MIF protein levels by Western blot. Actin was used as a loading control. (c) Quantification of Western blot by densitometry, using actin for standardization. The quantification data are means \pm SD of 4 independent experiments. $P$ values indicate statistically significant differences between MIF expression in the breast cancer cell lines compared to MCF-I2A. 
a

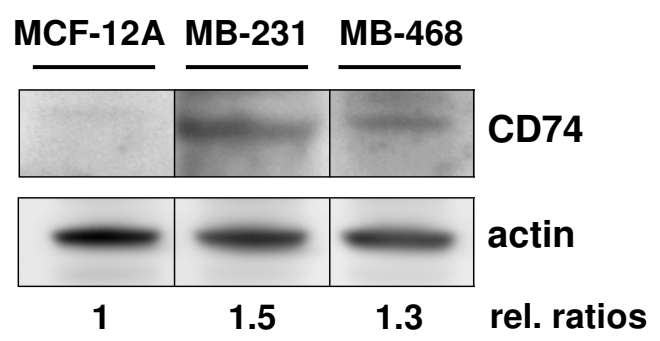

b
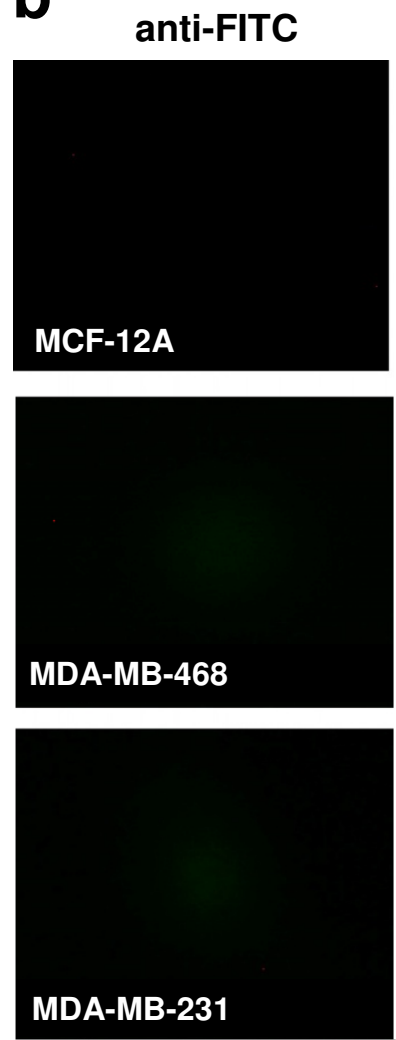

anti-FITC-CD74

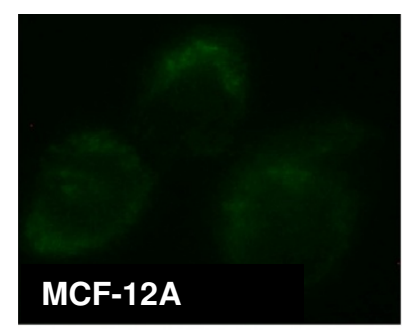

MDA-MB-468

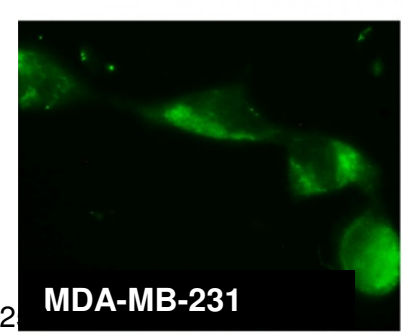

C
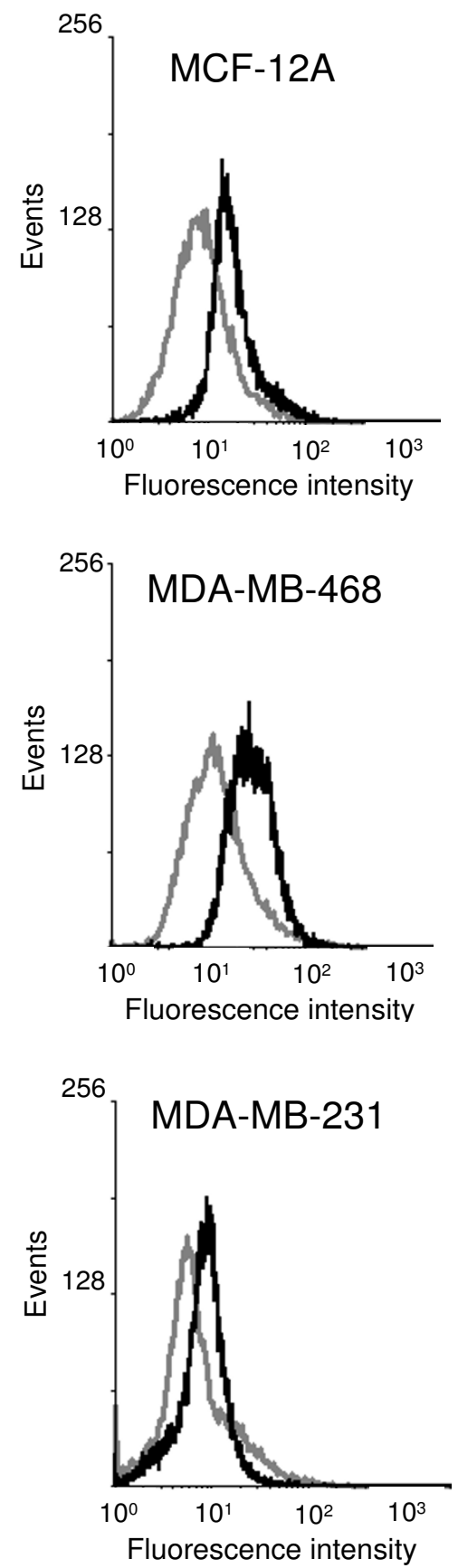

\section{Figure 2}

The MIF receptor CD74 is overexpressed in invasive MDA-MB-23 I cells. (a) Comparison of CD74 expression levels between MDA-MB-23I, non-invasive MDA-MB-468, and non-tumorous MCF-I2A cells by Western blot analysis. Lysates of non-stimulated cells were analysed by Western blot and band densitometry analysis against human CD74 and actin. Numbers indicate relative CD74/actin ratios. The quantification is representative of three independent experiments. (b) Comparison of CD74 expression levels between MDA-MB-23I, non-invasive MDA-MB-468, and non-tumorous MCF-I2A cells by fluorescence microscopy. Surface-expressed CD74 was revealed by FITC-labelled anti-CD $74 \mathrm{Ab}$. As a negative control, cells were labelled with a FITC-labelled secondary anti-mouse antibody. Photographs are representative of two independent experiments. 


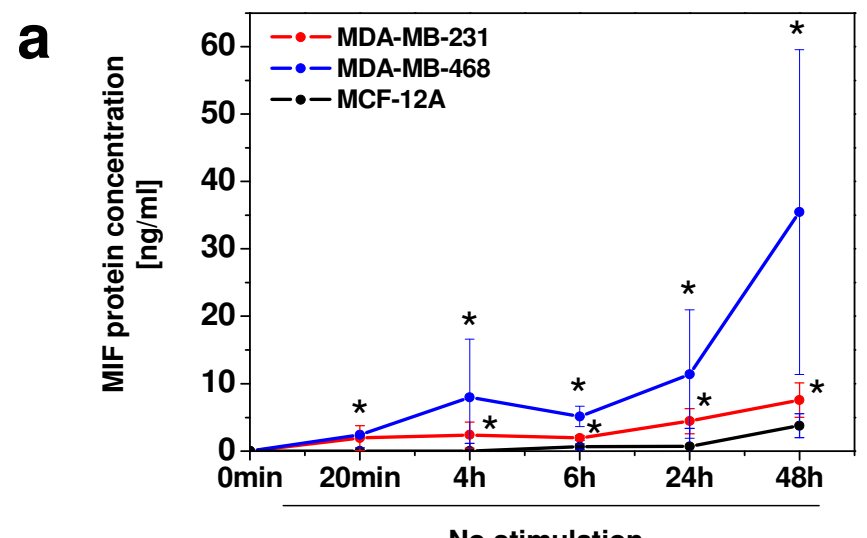

b
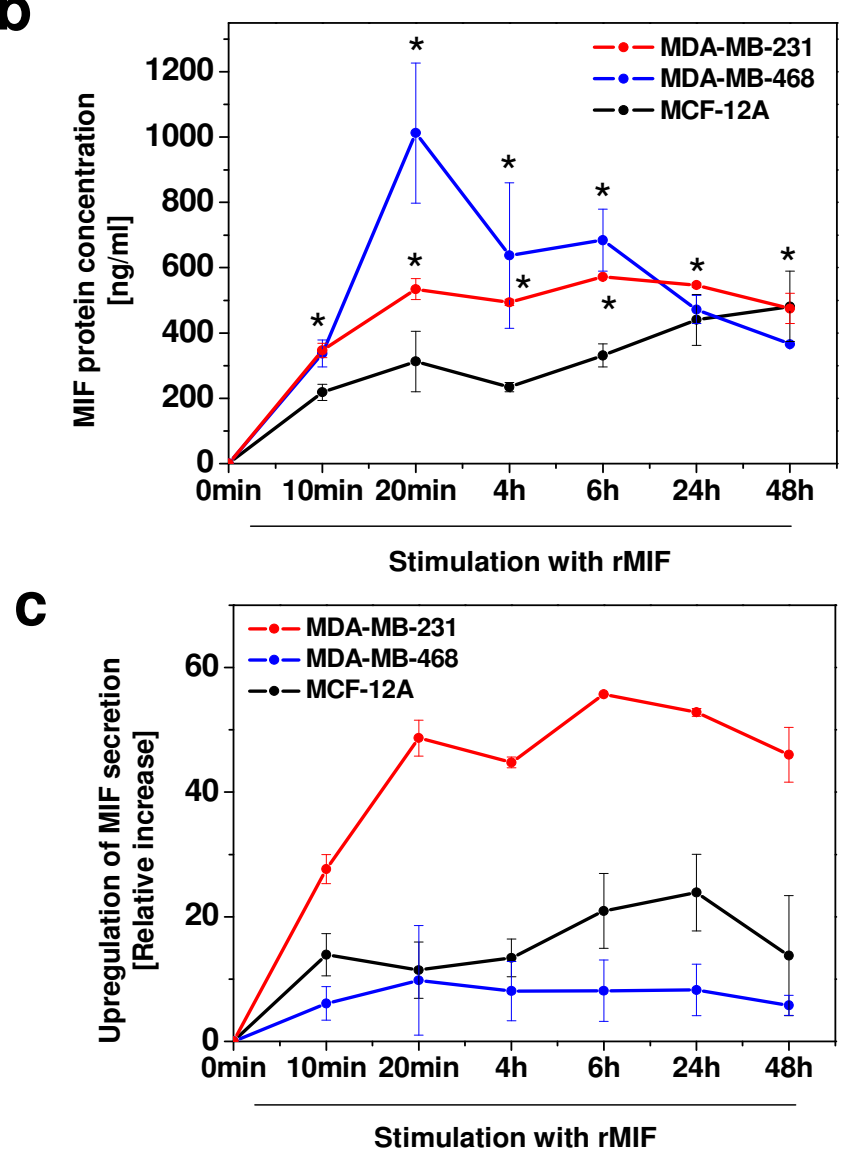

\section{Figure 3}

MIF secretion from breast cancer cells is upregulated by exogenous MIF. (a) Comparison of MIF secretion levels in unstimulated non-invasive MDA-MB-468, invasive MDA-MB-23I tumour cells, and MCF-I2A control cells. Supernatants of 100,000 cells were subjected to human MIF ELISA at the indicated time intervals. Of note, MDA-MB-468 cells secreted MIF levels of up to $35 \mathrm{ng} / \mathrm{ml}$. Asterisks indicate statistical significance compared to MCF-I2A. (b) Exogenous rMIF dramatically upregulates the secretion of MIF from breast cancer cells. As in (a), but stimulation of cells with $150 \mathrm{ng} / \mathrm{ml} \mathrm{rMIF}$ for the indicated time periods. Asterisks indicate statistical significance compared to MCF-I2A. (c) Invasive MDA-MB-23 I breast cancer cells exhibit the highest relative increase in MIF secretion. Relative increase of MIF secretion calculated from (b). To account for the addition of the $150 \mathrm{ng} / \mathrm{ml}$ exogenously added $\mathrm{rMIF}$, this value was subtracted for all incubations. Data represent means \pm SD of three determinations and two (b) or three (a and $\mathbf{c}$ ) independent experiments. 

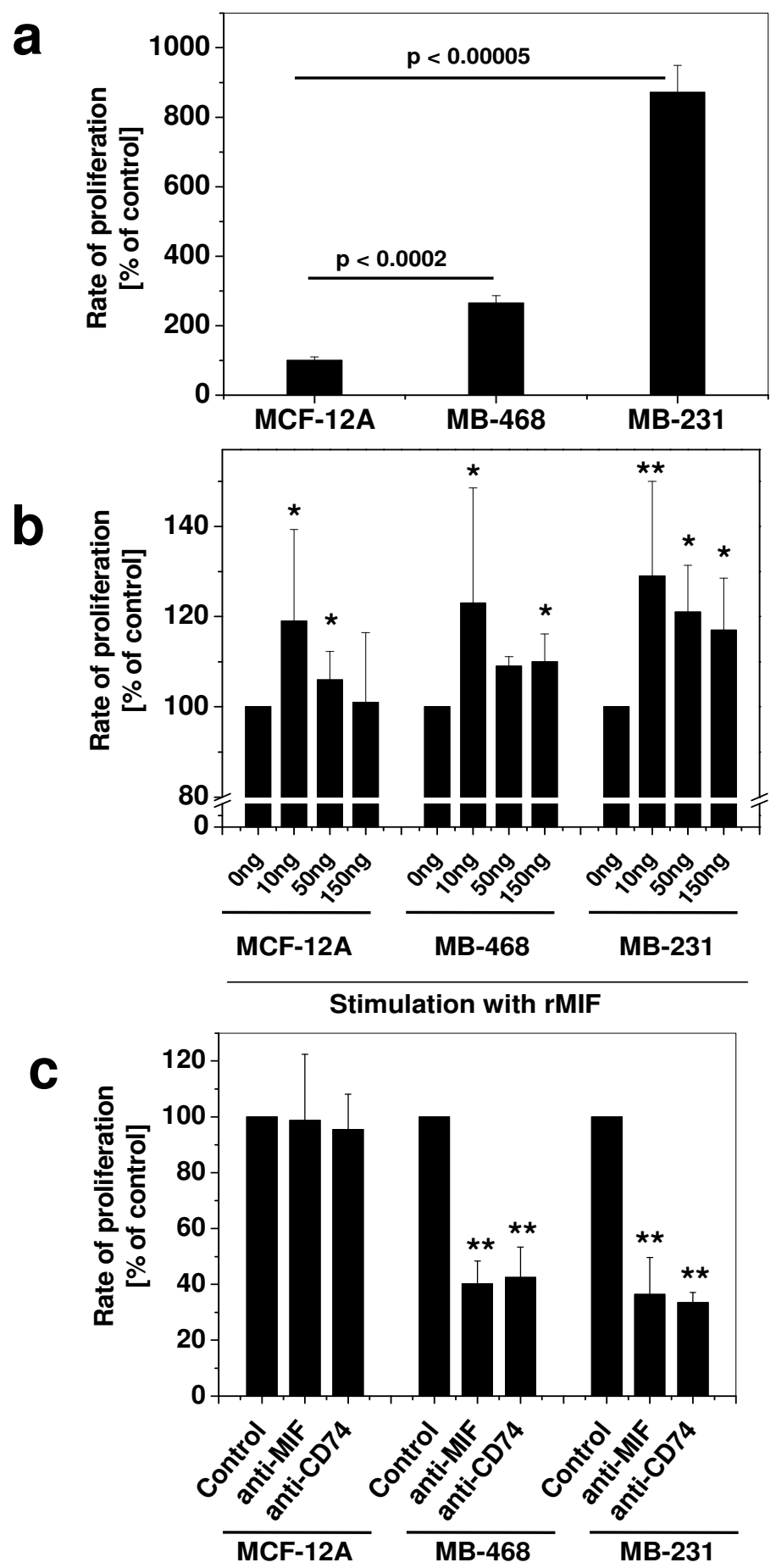

Figure 4 (see legend on next page) 
Figure 4 (see previous page)

MIF augments the proliferation rate of breast cancer cells. (a) Proliferation of unstimulated breast epithelial and breast carcinoma cell lines. Proliferation was measured by BrdU assay and is represented as percent of the baseline proliferation rate of MCF-I2A. Proliferation rates of MDA-MB-23I and -468 are markedly and significantly ( $P$ values indicated) higher than that of MCF-I2A. (b) Exogenous rMIF slightly but significantly enhances the proliferation rate of normal breast epithelial and breast carcinoma cell lines. As in (a) except that rMIF at indicated concentrations was added to cells for 24 h. Control cells $(0 \mathrm{ng} / \mathrm{ml})$ received control buffer (final dialysis refolding buffer). Asterisks indicate statistically significant differences compared to the corresponding control incubations: *, $\mathrm{p}<0.05$; **, $\mathrm{p}<0.0 \mathrm{I}$. (c) Endogenous MIF supports proliferation of breast cancer cells by an autocrine loop and inhibition of proliferation by anti-MIF and anti-CD74 antibodies. Unstimulated proliferation of breast cancer cells as in (a) was compared to that of MCF-I2A in the presence versus absence of neutralising anti-MIF and anti-CD74 antibodies. Control cells were incubated with equivalent amounts of PBS and isotype lgG had no effect (data not shown). Statistically significant differences (in comparison to cells not treated with antibody) are indicated by asterisks: *, $P$ $<0.05$; **, $\mathrm{p}<0.0$ I. Proliferation rates are means \pm SD of two $(\mathbf{b})$ or three $(\mathbf{a}, \mathbf{c})$ independent experiments with two $(\mathbf{a})$ or three $(\mathbf{b}, \mathbf{c})$ determinations.

proliferation rates induced by rMIF were moderate $(\leq 1.3-$ fold). To test for autocrine effects, cells were cultured under unstimulated conditions and endogenously produced MIF blocked by neutralizing anti-MIF antibody or by an antibody against CD74. Both antibodies, but not an isotype IgG, led to markedly reduced proliferation rates in MDA-MB-468 and MDA-MB-231 by $50-70 \%$. By contrast, proliferation of MCF-12A was not affected (Figure 4c). The remaining proliferation rates of $30-50 \%$ imply engagement of additional MIF signalling pathways such as the MIF/CXCR4 pathway [5].

In conjunction, these experiments showed that proliferation of both non-invasive and invasive breast cancer cells is driven by autocrine MIF action, encompassing the secretion of endogenous MIF and signalling through MIF/ CD74. It is of note that the breast cancer cell type exhibiting the highest overall (surface + endolysosomal) CD74 expression levels (see Figure 2), showed the greatest response to MIF.

\section{MIF promotes migration and invasion of breast cancer cells}

MIF has been demonstrated to directly and indirectly act as a chemoattractant for leukocytes, fibroblasts, and tumour cells $[5,36,37]$. To study the pro-invasive activities of MIF on breast cancer cell migration, MDA-MB-231 cells were calcein-labelled and subjected to Transwell assays applying Matrigel-coated filters. MIF significantly and dose-dependently stimulated the migration/invasion of MDA-MB-231 (Figure 5; maximum effect at $50 \mathrm{ng} / \mathrm{ml}$ rMIF). Thus, rMIF promotes the migration and invasion of breast cancer cells through basement membrane-like layers in a chemokine-like manner, confirming the notion that MIF produced in the microenvironment surrounding breast tumour cells may act in a pro-invasive manner.

\section{MIF is overexpressed in breast cancer tissue in vivo}

The in vitro studies suggested that exogenous MIF derived from the tumour microenvironment promotes proliferation, adhesion, and invasion of $\mathrm{CD}^{2} 4^{+}$invasive breast cancer cells. However, the association between MIF serum levels or MIF expression within breast cancer tissue and breast cancer progression in humans has been controversial. We thus performed a comprehensive retrospective study correlating MIF expression levels with clinical and pathological markers relevant in breast cancer using a tissue microarray (TMA) with 175 primary invasive breast cancers and 35 normal breast tissues. For patient characteristics see supplementary table (see Additional File 1). MIF protein expression was observed in normal breast epithelial cells (Figure 6a, b) and breast tumour cells (Figure $6 \mathrm{c}-\mathrm{e}$ ). Although MIF expression was variable in both normal and malignant breast tissue, abundant MIF expression was predominantly found in tumour cells. Overall, we found that MIF levels were upregulated in breast cancer tissue compared to normal breast epithelium according a semi-quantitative immunoreactivity score (Remmele and Stegner; Figure 6g).

\section{High MIF expression in breast tumour tissue correlates with tumour size and hormone receptor status and is associated with favourable survival}

Next, we correlated MIF expression levels in primary human breast cancer with clinicopathological parameters. Table 1 shows the correlations obtained when high (IRS = 6-12) and low (IRS = 0-4) MIF expression was compared by descriptive Fisher's exact test with tumour size, lymph node status [38], histological grade, as well as estrogen (ER), progesterone (PR), and epidermal growth factor (EGFR) receptor status. MIF expression was highly significantly associated with tumour size (pT) in an inverse manner $(p=0.007)$. Thus large tumours $(>2 \mathrm{~cm})$ being associated with poor prognosis predominantly expressed low levels of MIF $($ IRS $<4)$. A highly significant positive correlation was found between abundant MIF expression 
a

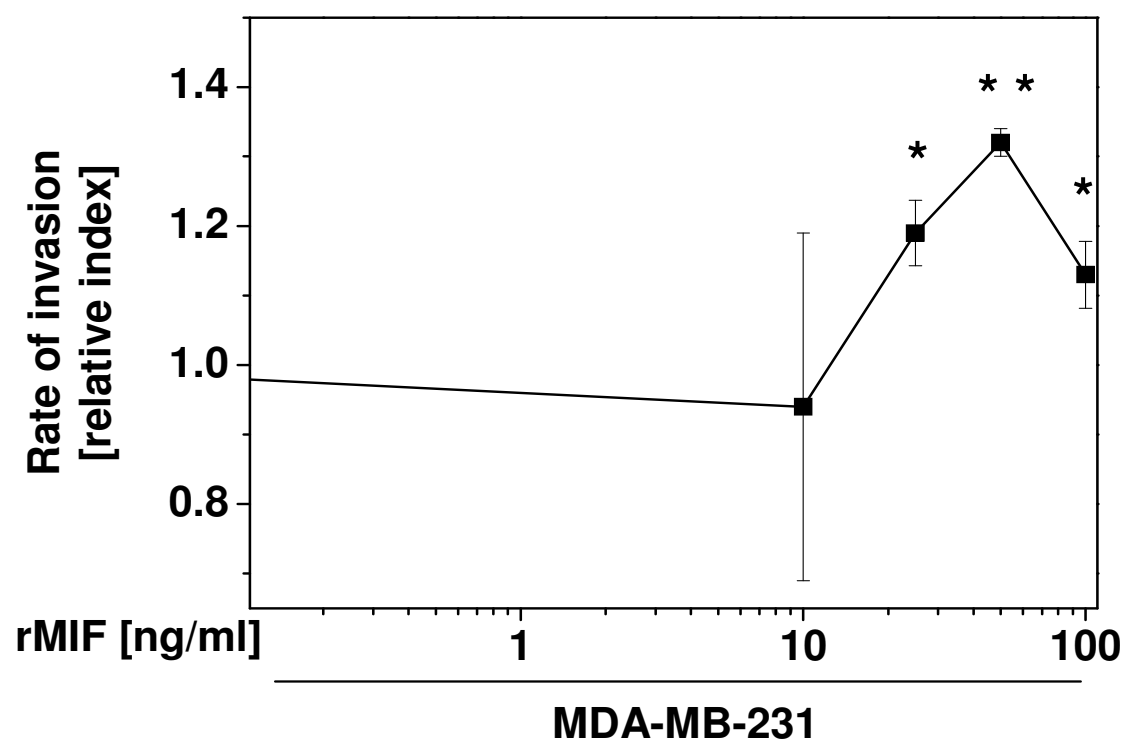

b
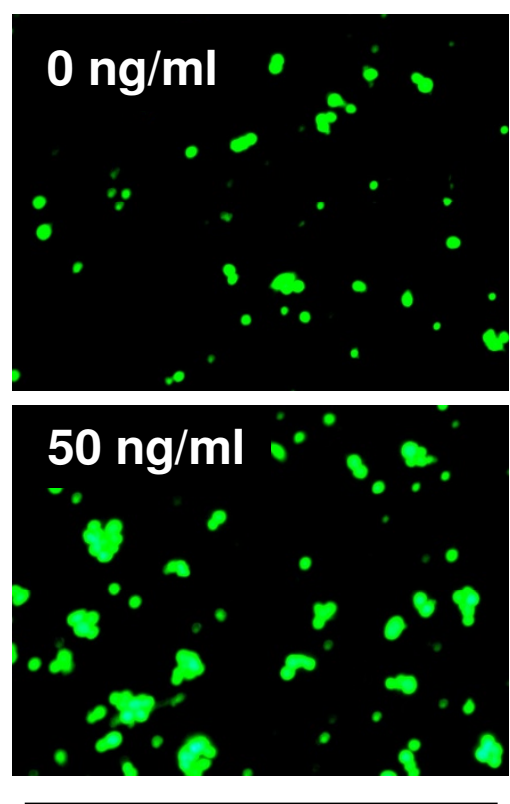

MDA-MB-231

\section{Figure 5}

MIF promotes the migration and invasion of breast cancer cells. Invasive MDA-MB-23I cells were incubated in the upper Matrigel-coated insert of a Transwell chamber and their migration and invasion measured in response to rMIF added as a chemoattractant to the lower chamber at indicated concentrations. Invaded Calcein-labelled cells were counted by fluorescence microscopy. (a) Quantification of 5 independent experiments taking 10 pictures each. Data points are means \pm SD and asterisks indicate significant increases of the invasion rate $(*, p<0.05 ; * *, p<0.01)$. (b) Representative fluorescence microscopy images comparing the effect $50 \mathrm{ng} / \mathrm{ml}$ MIF with a control incubation ( $0 \mathrm{ng} / \mathrm{ml}$ MIF). 

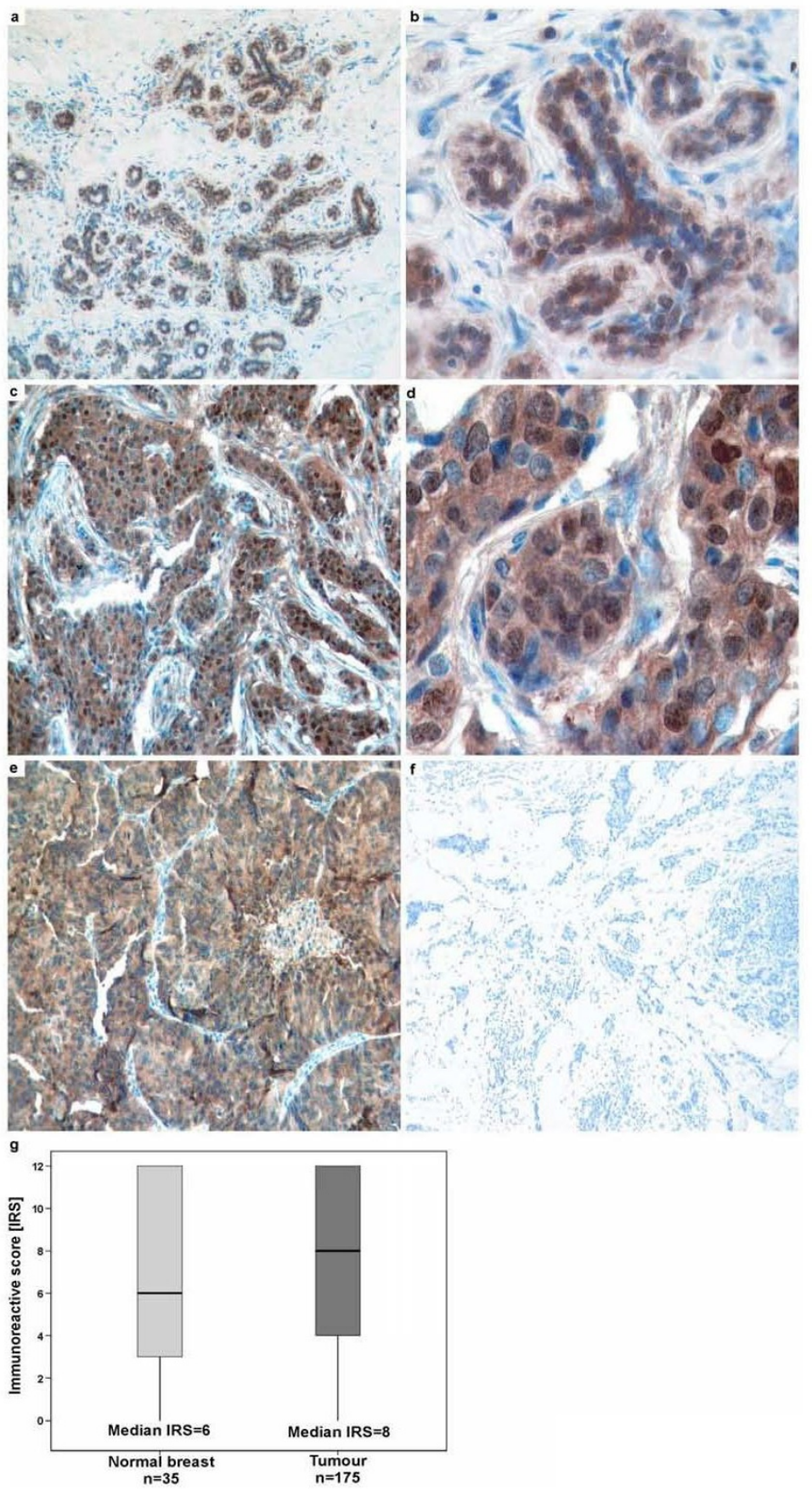

\section{Figure 6}

MIF is overexpressed in breast cancer tissue. (a-f) Immunohistochemical stainings of MIF protein expression on a tissue microarray (TMA) of human breast cancer tissue specimens. Representative stainings applying a MIF antibody are shown. (a, b) Normal breast epithelia with moderate MIF protein expression (IRS $=4)$. (c, d) Invasive breast tumour with strong MIF protein expression (IRS = 8). (e, f) Samples of invasive mamma carcinoma were used as positive and negative control. For negative control, the primary antibody was omitted. Original magnifications: $100 \times$ for a, c, e, f; 400x for b, d. (g) Box plot analysis illustrating the distribution of MIF protein expression in normal breast tissue and breast cancer tissue. The $y$ axis indicates the IRS of cytoplasmic MIF protein staining in normal $(n=35)$ and breast cancer tissue $(n=175)$ analysed on the TMA. Median MIF expression was found to be increased in human breast tumours (median IRS $=8$ ) compared to normal breast epithelia (median IRS = 6). Horizontal lines: group medians; boxes: $25-75 \%$ quartiles; vertical lines: range and minimum. 
Table I: Clinicopathological parameters in relation to MIF protein expression

\begin{tabular}{|c|c|c|c|c|}
\hline \multirow[b]{2}{*}{ Variable } & \multicolumn{4}{|c|}{ MIF protein expression } \\
\hline & $\mathbf{n}^{\mathbf{a}}$ & IRS (0-4) & IRS (6-I2) & P value ${ }^{d}$ \\
\hline \multicolumn{5}{|l|}{ Tumour size } \\
\hline PTI & 48 & 13 & 35 & 0.007 \\
\hline pT2 & 86 & 24 & 62 & \\
\hline PT3 & 12 & 3 & 9 & \\
\hline $\mathrm{pT} 4$ & 27 & 16 & 11 & \\
\hline \multicolumn{5}{|l|}{ Lymph node status ${ }^{b}$} \\
\hline pNO & 67 & 17 & 50 & 0.190 \\
\hline pNI-3 & 100 & 35 & 65 & \\
\hline \multicolumn{5}{|l|}{ Histological grade } \\
\hline GI & 19 & 9 & 10 & 0.933 \\
\hline G2 & 73 & 18 & 55 & \\
\hline G3 & 79 & 29 & 50 & \\
\hline \multicolumn{5}{|l|}{ Histological type } \\
\hline invasive ductal & 145 & 51 & 94 & 0.496 \\
\hline invasive lobular & 13 & 3 & 10 & \\
\hline other & 17 & 5 & 12 & \\
\hline \multicolumn{5}{|l|}{ Estrogen receptor status } \\
\hline negative (IRSc $0-2$ ) & 46 & 21 & 25 & 0.028 \\
\hline positive (IRS 3-I2) & 96 & 26 & 70 & \\
\hline \multicolumn{5}{|c|}{ Progesterone receptor status } \\
\hline negative (IRS 0-2) & 101 & 39 & 62 & 0.006 \\
\hline positive (IRS 3-12) & 49 & 8 & 41 & \\
\hline \multicolumn{5}{|l|}{ EGFR status } \\
\hline negative (IRS 0) & 65 & 28 & 37 & 0.038 \\
\hline positive (IRS I-3) & 92 & 25 & 67 & \\
\hline
\end{tabular}

a Only female patients with primary, unilateral, invasive breast cancer were included. Significant $\mathrm{p}$ values are marked in bold face. ${ }^{b}$ According to the TNM classification of Sobin and Wittekind [38]. ${ }^{c}$ IRS $=$ immunoreactive score according to Remmele and Stegner [35]. ${ }^{d}$ Fisher's exact test.

Significant $p$ values are marked in bold face.

and PR status $(\mathrm{p}=0.006)$. In addition, positive correlations with the ER and EGFR status were measured ( $\mathrm{p}=$ 0.028 and $\mathrm{p}=0.038$, respectively). Thus surprisingly, abundant MIF expression in breast tumour tissue correlates with markers associated with a favourable prognosis, i.e. PT, positive ER and PR status. No correlations were observed with lymph node status and histological grade.

The obtained correlation between MIF expression in breast tumour tissue and tumour size and hormone receptor levels tempted us to postulate that MIF overexpression might be correlated with increased tumour-specific survival in breast cancer patients. Patients with strong cytosolic MIF expression in the breast cancer tissue (IRS = 6-12) showed a highly significant increase in overall survival (OS) compared to the MIF low expresser group with an IRS $=0-4$ (5-year OS $=67 \%$ versus $50 \%$, respectively; $\mathrm{p}=0.0019$; Figure 7 and Table 2). In line with these findings, 5-year recurrence-free survival (RFS) was $52 \%$ in the MIF high expressers compared to $36 \%$ in the low expressers ( $p=0.0327$; Figure 7 and Table 2). IRS analysis of the PR status paralleled that of MIF with high PR concentra- tions correlating with increased OS and RFS rates ( $\mathrm{p}<$ 0.001 and $\mathrm{p}=0.01$, respectively). Of note, tumour size, lymph node status, and histological grade positively and significantly correlated with OS and RFS in our cohort of breast cancer patients underscoring the suitability of this cohort to analyse new prognostic marker molecules. Multivariate Cox regression models including factors possibly influencing OS/RFS in relation to MIF protein expression failed to exhibit significance, indicating that MIF is not an independent prognostic marker in breast cancer, probably due to its close relation to hormone receptor status (data not shown).

\section{Discussion}

MIF is not only a mediator of acute and chronic inflammatory conditions [1], but also plays a role in cancerogenesis. MIF overexpression has been observed in several human tumours and molecular links between MIF and p53, apoptosis, JAB1/CSN5, and cell cycle regulation $[6,7,18,22,23,39]$ suggest that MIF is important in regulating the balance between cell homeostasis and neoplastic behaviour. Moreover, MIF has angiogenic potential and 


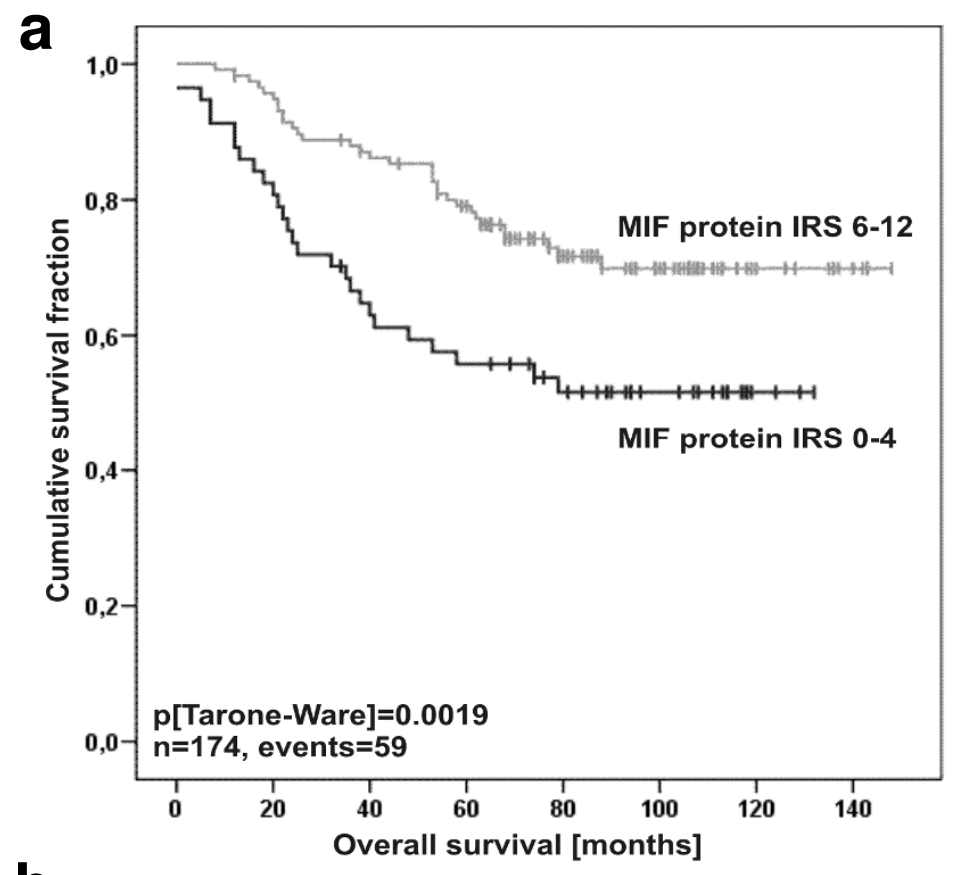

b

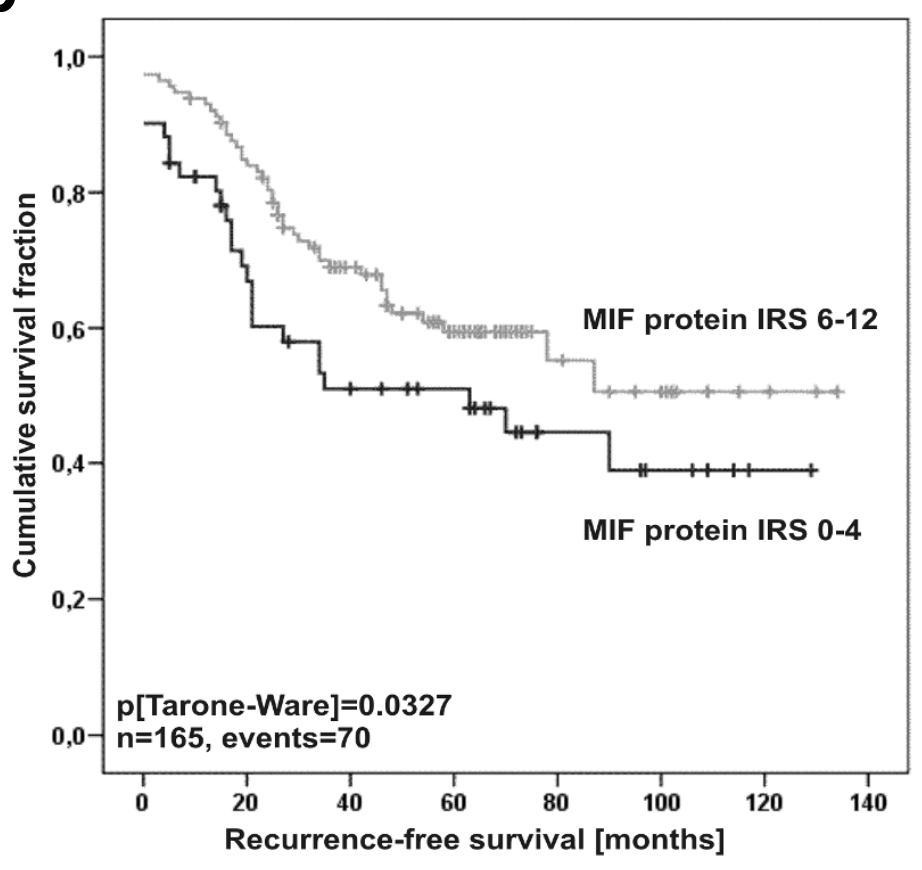

\section{Figure 7}

High MIF expression in breast tumour tissue positively correlates with survival. Kaplan-Meier analyses of overall survival (OS) (a) and recurrence-free survival (RFS) (b) in relation to MIFprotein expression in breast cancer tissue specimens of 174 and 165 patients, respectively. Distribution of time (months)- and tumour-related death among 174 breast cancer patients with abundant (upper graph) or low (lower graph) MIF expression is shown. (a) Patients featuring low MIF protein expression (IRS $=0-4$ ) have a reduced estimated mean five-year OS survival rate of $50 \%$ compared to $67 \%$ survival probability for patients with strong MIF expression (IRS = 6-12). (b) Patients exhibiting low MIF protein expression (IRS $=0-4$ ) have an increased risk for tumour relapse (mean RFS rate of 52\%) after five years compared to $36 \%$ for patients with strong MIF expression (IRS = 6-I2). 
Table 2: Univariate analysis of clinicopathological parameters influencing recurrence-free survival (RFS) and overall survival (OS).

\begin{tabular}{|c|c|c|c|c|c|c|}
\hline \multirow[t]{2}{*}{ Variable } & \multicolumn{3}{|c|}{ RFS } & \multicolumn{3}{|c|}{ OS } \\
\hline & $\mathbf{n}^{\mathbf{a}}$ & events & p valued & $\mathbf{n}$ & events & $p$ value \\
\hline \multicolumn{7}{|c|}{ Clinicopathological factors: } \\
\hline \multicolumn{7}{|l|}{ Tumour size } \\
\hline PTI & 46 & 10 & & 48 & 8 & \\
\hline pT2 & 83 & 39 & & 86 & 30 & \\
\hline pT3 & 11 & 5 & $<0.001$ & 12 & 3 & 0.001 \\
\hline pT4 & 24 & 16 & & 27 & 18 & \\
\hline \multicolumn{7}{|l|}{ Lymph node status ${ }^{\mathrm{b}}$} \\
\hline pNO & 66 & 14 & & 68 & 11 & \\
\hline $\mathrm{pNI}-3$ & 97 & 53 & $<0.001$ & 101 & 44 & $<0.001$ \\
\hline \multicolumn{7}{|l|}{ Histological grade } \\
\hline GI & 18 & 4 & & 19 & 5 & \\
\hline G2 & 69 & 23 & & 74 & 18 & \\
\hline G3 & 78 & 43 & $<0.001$ & 80 & 37 & 0.003 \\
\hline \multicolumn{7}{|l|}{ Histological type } \\
\hline invasive ductal & 138 & 63 & & 142 & 50 & \\
\hline invasive lobular & 12 & 3 & & 14 & 5 & \\
\hline other & 15 & 4 & 0.167 & 17 & 5 & 0.876 \\
\hline \multicolumn{7}{|c|}{ Estrogen receptor status } \\
\hline negative (IRSc $0-2$ ) & 46 & 24 & & 46 & 19 & \\
\hline positive (IRS 3-I2) & 93 & 32 & 0.065 & 98 & 28 & 0.076 \\
\hline \multicolumn{7}{|c|}{ Progesterone receptor status } \\
\hline negative (IRSc $0-2$ ) & 95 & 48 & & 102 & 44 & \\
\hline positive (IRS 3-12) & 50 & 13 & 0.010 & 50 & 8 & $<0.001$ \\
\hline \multicolumn{7}{|l|}{ MIF protein expression } \\
\hline weak (IRSc 0-4) & 51 & 26 & & 57 & 27 & \\
\hline strong (IRS 5-12) & 114 & 44 & 0.033 & 117 & 32 & 0.002 \\
\hline \multicolumn{7}{|l|}{ EGFR status } \\
\hline negative (IRSc 0 ) & 59 & 21 & & 65 & 23 & \\
\hline positive (IRS I-3) & 91 & 44 & 0.146 & 93 & 35 & 0.867 \\
\hline
\end{tabular}

a Only female patients with primary, unilateral, invasive breast cancer were included. ${ }^{b}$ According to the TNM classification of Sobin and Wittekind [38]. c IRS = immunoreactive score according to Remmele and Stegner [35]. ${ }^{d}$ Fisher's exact test. Significant $p$ values are marked in bold face.

enhances the expression of proangiogenic CXCL8 and vascular endothelial growth factor (VEGF) $[37,40]$. Interestingly, MIF exhibits similarities with CXCL8 and shares with this chemokine an ELR-like motif [41]. In fact, MIF acts as a non-cognate ligand of CXCR2 and drives leukocyte recruitment through CXCR2 [5]. Thus, MIF is a cytokine/chemokine and autocrine/paracrine growth factor promoting tumourigenesis.

Only a few studies have addressed the role of MIF in breast cancer. Bando and colleagues noticed MIF overexpression in 93 primary breast cancer tissues with MIF localizing to tumour as well as stromal cells including TAMs [12]. Of note, in that cohort intra-tumoural MIF levels and circulating MIF inversely correlated with nodal status. Intratumoural MIF levels correlated with proinflammatory macrophage cytokines, suggesting that MIF regulates and is regulated by tumour-stroma interactions, particularly in cancers with minimal nodal spread [12]. While the overexpression of MIF in primary human breast cancer tissue was recently confirmed [31], analysis of that cohort (85 patients with MIF-positive and 36 patients with MIF-neg- ative tumours) revealed that positive MIF expression was associated with unfavourable disease-free, but not overall, survival. This latter study also demonstrated that MIF levels in breast tumour tissue correlated with tumour CXCL8 levels, whereas no correlations with steroid hormone receptor status were observed [31]. Thus, while there is consensus from these reports that MIF is overexpressed in human breast cancer, its functional correlation with breast tumourigenesis has remained unclear. In own prior work leading up to the current investigation, we observed strong MIF expression in MCF-7 and ZR-75-1 breast cancer cells, and blockade of MIF secreted from these cells suggested a causal role of extracellular MIF in breast cancer cell survival involving the AKT/PI3K pathway [21]. These findings are in favour of a pro-tumourigenic role of MIF. Similarly, Hagemann et al. demonstrated that MIF enhanced MCF-7 invasiveness and matrix metalloproteinase-9 (MMP-9) activity. When coculturing MCF-7 cells with human macrophages, MIF was identified as a prominent target in tumour cells that was upregulated upon inflammatory cytokine production by cocultured macrophages. In turn, induced tumour cell-derived MIF was crit- 
ical for invasiveness of tumour cells and MMP9 secretion by macrophages [32]. In conjunction, these prior and in part conflicting studies indicate that despite its established overexpression in breast cancer, the contribution of MIF to breast cancerogenesis is likely to be complex and may vary between disease stages. The precise function of MIF may depend on its cellular expression (intracellular, extracellular, breast or stromal cell-derived).

To address these possibilities and to comprehensively explore MIF's role in breast cancerogenesis, we correlated MIF expression levels with clinicopathological data in a large cohort of patients with invasive breast cancer and studied the effect of MIF on the behaviour of breast cancer cell lines in vitro. While we confirmed that MIF was markedly overexpressed in non-invasive MDA-MB-468 and ZR75-1 breast cancer cells, compared to benign MCF-12A breast cells, the highly invasive MDA-MB-231 cancer cells surprisingly showed low MIF expression levels. In contrast, expression of the MIF receptor CD74 was elevated in MDA-MB-231. This suggested that invasive breast cancer cells are target cells of MIF in breast cancer. Indeed, exogenous MIF stimulated MDA-MB-231 proliferation, and blockade of CD74 blocked MDA-MB-231 proliferation induced by autocrine MIF activity. However, enhanced CD74-dependent tumour cell proliferation by autocrine MIF was also measured in MDA-MB-468 cells. These cells also expressed some surface CD74, an observation that explained their responsiveness, but contained markedly reduced levels of total cellular CD74. Only a small portion of CD74 is presented at the cell surface at any given time point, whereas the majority is localized in the endolysosomal compartment. It will be of interest to study, whether signalling from MIF/CD74 complexes originates from the cell surface or is activated from signalling endosomes. In line with our results, secretion of MIF by tumour cells and autocrine stimulation of neoplastic behaviour by MIF has previously been observed for several tumour cell types [14,32,42].

MIF is expressed in numerous cell types including tumour cells. Preformed MIF protein resides in the cytosol, from where it is secreted by a non-conventional pathway upon stimulation. Stimuli such as endotoxin, inflammatory cytokines, or oxidized lipids have all been demonstrated to be potent triggers of MIF secretion $[1,43]$. Autocrine MIF activation loops have been implicated in tumour cell growth. Here we tested whether exogenous MIF would induce MIF secretion. Both MDA-MB-231 and MDA-MB468 breast cancer cells slowly secreted MIF during unstimulated cultivation. Unspecific cell death could be excluded (data not shown). Stimulation of cells rMIF led to a dramatic upregulation of the secretion rate of endogenous MIF of up to $500-1000 \mathrm{ng} / \mathrm{ml}$ in MDA-MB-468 and MDAMB-231. Peak secretion occurred after $20 \mathrm{~min}$, indicating that exogenous MIF triggered massive release of preformed MIF stores. Relative upregulation rates over background secretion and added rMIF were even more striking. MIF secretion in invasive MDA-MB-231 cells increased 28-fold after $10 \mathrm{~min}$ and reached a sustained rate of 50-fold thereafter. It is worthwhile of mentioning that the concentration of rMIF found to trigger optimal release of endogenous MIF was $150 \mathrm{ng} / \mathrm{ml}$. Although this rMIF concentration is well within the range of MIF concentrations measured and known in pathophysiologic conditions to promote inflammation and pro-tumourigenic behaviour, it is currently mechanistically unclear why lower concentrations of rMIF (10-50 ng/ml) sufficed to lead to an enhancement of breast cancer cell proliferation and invasion. Thus, invasive breast cancer cells exhibiting low MIF expression and secretion levels at baseline are capable of dramatically upregulating MIF upon short term triggering with exogenous MIF, possibly derived from tumour/stroma interactions.

We found that anti-MIF and anti-CD74 antibodies potently blocked breast cancer cell proliferation induced by autocrine or exogenous MIF. Thus, as observed in prostate and gastric cancer $[25,26], \mathrm{MIF} / \mathrm{CD} 74$ interactions appear to play a role in breast tumourigenesis. It is interesting to note, that upon MIF binding CD74 associates with CD44 and signalling induced by MIF/CD74/CD44 has been implicated in increased B cell survival [28]. The role of the various known CD44 variants in breast cancer is a matter of debate [29]. Recent reports indicate that CD44 overexpression could to be associated with an increased disease-free survival of patients suffering from node-negative invasive breast carcinomas $[30,44]$. However, numerous other studies have suggested that CD44 promotes invasiveness of breast cancer cells [45-47]. Thus, future studies should address the role of CD74/CD44 complexes in MDA-MB-231 invasion.

In conjunction with the study by Hagemann et al., it may be speculated that in human breast cancer tissue, TAMderived MIF triggers breast cancer cell activation. In fact, the assumption that MIF promotes breast tumour cell invasiveness was underscored by Matrigel invasion assays using MDA-MB-231. The transmigration rate of these cells through Matrigel was markedly enhanced when rMIF was added to the lower chamber, in line with recent observations demonstrating that MIF functions as a chemoattractant $[5,48]$. Furthermore, the tremendous increase in the rate of MIF secretion as observed in breast cancer cells following stimulation with rMIF suggests that TAM-derived MIF could trigger MIF secretion from breast cancer cells, thus igniting a local MIF amplification loop. In turn, as manifest from the study of Hagemann [32], breast cancer cell-derived MIF might then modulate (pro-invasive) TAM activities as well as induce a broad range of inflam- 
matory processes, including the elevated expression of secondary mediators that may further promote tumourigenesis $[14,22]$.

As MIF is expressed in breast cancer cell lines, promotes breast tumour cell proliferation and invasion, and contributes to stroma/tumour interactions, one may expect that MIF is overexpressed in breast cancer in vivo and would correlate with a poor survival prognosis and markers such as EGFR or HER2 [49].

We compared intra-tumoural MIF levels in specimens from 175 breast cancer patients with those of 35 normal breast tissues. Confirming earlier studies by Bando et al. [12] and $\mathrm{Xu}$ and colleagues [31], we found that MIF protein was significantly upregulated in breast cancer tissues compared to normal breast epithelium. However, there are differences between our study and the two previous investigations. We detected substantial but varying concentrations of MIF protein in essentially all tumour cells, where MIF was primarily localised in the cytosol. In contrast, Bando and colleagues in their cohort of 93 primary cancer tissues predominantly observed nuclear MIF staining. In the cohort studied by Xu et al., surprisingly only $1 /$ 3 of the patients $(n=36)$ had MIF-positive breast cancer tissues. $\mathrm{Xu}$ et al. used a polyclonal anti-MIF antibody, whereas in our study the highly specific anti-MIF MAB 289 was applied.

At first sight, our in vitro data are in contrast to the correlations observed in vivo. We noticed a significant positive correlation between MIF levels and hormone receptors (especially PR) and a significant negative correlation between MIF and tumour size. PR and ER are markers of a favourable prognosis in breast cancer and characterize specific subtypes of the disease. Xu et al. did not detect any correlation between MIF and ER or PR in their cohort, but picked up a positive correlation with EGFR, with which we also see a moderately significant correlation ( $\mathrm{p}=0.038)$. Bando et al. only measured ER and found no correlation with MIF. Despite these differences that may in part be due to the different cohorts studied, the link between MIF levels and ER/PR status as observed in our cohort is of interest, because these parameters may be molecularly connected to MIF through JAB1/CSN5, which is abundantly expressed in breast cancer [50]. JAB1 is an intracellular binding partner of MIF [7] and has been demonstrated to interact with ER and PR [51].

All three studies concur in failing to see any correlations between breast cancer MIF expression levels and tumour size or histological tumour grades [12,31]. Interestingly, Bando et al. noticed that MIF levels in breast tumour tissue were inversely correlated with nodal status. However, no such correlation was detected in our study and in the study by Xu et al.. The observation that abundant MIF expression is significantly associated with breast tumours of small size supports the notion that intracellular MIF can inhibit tumour cell proliferation. This hypothesis is underscored by the finding that breast cancer patients with abundant MIF expression have a favourable prognosis both according to tumour-specific OS and RFS. The strong statistical significance of these data suggests that high levels of MIF expressed in the cytosol of breast carcinoma cells are beneficial for the outcome of breast cancer.

Thus, there appears to be a dichotomy of MIF functions in breast cancer progression. We speculate that intracellular MIF in the breast cells has a protective function, whereas extracellular MIF, be it TAM-derived or produced by carcinoma cells upon stroma/tumour interactions, is pathogenic. The anti-tumour effect of cytosolic breast epithelial MIF might be mediated through JAB1/CSN5 which promotes p27 degradation [52] and is counter-regulated by MIF [7] or could reflect cell homeostatic activities of MIF $[23,53]$. Pro-tumourigenic effects of extracellular MIF have been reported [31,32] and could be due to MMP activation, or MIF's pro-angiogenic and inflammatory activity. In fact, it was suggested that MIF is a determinant of the M1-subtype of TAMs and that mammary adenocarcinoma cells lead to MIF ablation in M1-TAMs, inducing a switch towards M2 polarization [54].

\section{Conclusion}

This study in conjunction with prior observations by others indicates that MIF has a dual role in breast cancer. Intracellular MIF localised to breast cancer cells may be indicative of a favourable prognosis, whereas extracellular breast tumour tissue-derived MIF could be proinflammatory and will likely constitute an unfavourable prognosis marker.

\section{List of abbreviations}

ER: estrogen receptor; EGFR: epidermal growth factor receptor; IRS: immunoreactive score; JAB1/CSN5: c-Jun activation domain binding protein-1/COP 9 signalosome subunit 5; MIF: macrophage migration inhibitory factor; MMP: matrix metalloproteinase; OS: overall survival; PR: progesterone receptor; RFS: recurrence-free survival; TAM: tumour-associated macrophage; TMA: tissue microarray.

\section{Competing interests}

J.B. is an inventor on patent applications on anti-MIF strategies. The other authors declare that they have no competing interests.

\section{Authors' contributions}

EV and EN carried out most of the experiments, participated in data analysis, and assisted in drafting the manuscript. NB participated in TMA analysis; AS, HL, and BL 
participated in the in vitro experiments. AH provided the TMA and participated in data analysis. ED conceived the TMA part of the study, participated in experiment design and data analysis, wrote parts of the manuscript, and revised the manuscript. JB conceived the in vitro part of the study as well as the overall study, participated in experiment design and data analysis, and wrote and revised the manuscript. All authors read and approved the final manuscript.

\section{Additional material}

\section{Additional file 1}

Clinicopathological parameters of breast cancer specimens. The table shows clinicopathological parameters of 175 breast cancer specimens analysed on a tissue microarray.

Click here for file

[http://www.biomedcentral.com/content/supplementary/14712407-9-230-S1.doc]

\section{Acknowledgements}

We are grateful to S. Kraemer, M. Jung, A. Kapurniotu, C. Weber, and B. Lüscher for helpful discussions and to I. Losen and M. Dewor for technical help with the TMAs and rMIF preparations. Supported by DFG grants SFB542/TP-A7 and START grant 696055 to J.B., and by START-grant 696050 to E.D.

\section{References}

I. Calandra T, Roger T: Macrophage migration inhibitory factor: A regulator of innate immunity. Nat Rev Immunol 2003, 3:791-800.

2. Lue H, Kleemann R, Calandra T, Roger T, Bernhagen J: Macrophage migration inhibitory factor (MIF): Mechanisms of action and role in disease. Microb Infect 2002, 4:449-460.

3. Morand EF, Leech M, Bernhagen J: MIF: a new cytokine link between rheumatoid arthritis and atherosclerosis. Nat Rev Drug Discov 2006, 5:399-4I0.

4. Zernecke A, Bernhagen J, Weber C: Macrophage migration inhibitory factor in cardiovascular disease. Circulation 2008, | | 7:| 594-1602.

5. Bernhagen J, Krohn R, Lue H, Gregory JL, Zernecke A, Koenen RR, Dewor M, Georgiev I, Schober A, Leng L, Kooistra T, Fingerle-Rowson G, Ghezzi P, Kleemann R, McColl SR, Bucala R, Hickey MJ, Weber $C$ : $M I F$ is a noncognate ligand of $C X C$ chemokine receptors in inflammatory and atherogenic cell recruitment. Nat Med 2007, I 3:587-596.

6. Hudson JD, Shoaibi MA, Maestro R, Carnero A, Hannon GJ, Beach $\mathrm{DH}$ : A proinflammatory cytokine inhibits p53 tumor suppressor activity. I Exp Med 1999, I90:1375-। 382

7. Kleemann R, Hausser A, Geiger G, Mischke R, Burger-Kentischer A, Flieger O, Johannes FJ, Roger T, Calandra T, Kapurniotu A, Grell M, Finkelmeier D, Brunner H, Bernhagen J: Intracellular action of the cytokine MIF to modulate AP-I activity and the cell cycle through Jab I. Nature 2000, 408:2II-2I6.

8. Kleemann R, Kapurniotu A, Mischke R, Held J, Bernhagen J: Characterization of catalytic center mutants of macrophage migration inhibitory factor (MIF) and comparison with C8IS MIF. Eur J Biochem 1999, 26 I:753-766.

9. Mitchell RA, Metz CN, Peng T, Bucala R: Sustained mitogen-activated protein kinase (MAPK) and cytoplasmic phospholipase A2 activation by macrophage migration inhibitory factor (MIF). Regulatory role in cell proliferation and glucocorticoid action. J Biol Chem 1999, 274:18100-18106.
10. Wilson JM, Coletta PL, Cuthbert RJ, Scott N, MacLennan K, Hawcroft G, Leng L, Lubetsky JB, Jin KK, Lolis E, Medina F, Brieva JA, Poulsom R, Markham AF, Bucala R, Hull MA: Macrophage migration inhibitory factor promotes intestinal tumorigenesis. Gastroenterology 2005, I 29: I 485-I503.

II. Meyer-Siegler KL, Iczkowski KA, Vera PL: Further evidence for increased macrophage migration inhibitory factor expression in prostate cancer. BMC Cancer 2005, 5:73.

12. Bando $H$, Matsumoto $G$, Bando M, Muta M, Ogawa T, Funata $N$, Nishihira J, Koike $M$, Toi M: Expression of macrophage migration inhibitory factor in human breast cancer: association with nodal spread. Ipn / Cancer Res 2002, 93:389-396.

13. Chesney J, Metz C, Bacher M, Peng T, Meinhardt A, Bucala R: An essential role for macrophage migration inhibitory factor (MIF) in angiogenesis and the growth of a murine lymphoma. Mol Med 1999, 5:181-191.

14. Mitchell RA, Bucala R: Tumor growth-promoting properties of macrophage migration inhibitory factor. Semin Cancer Biol 2000, 10:359-366.

15. Nishihira J, Ishibashi T, Fukushima T, Sun B, Sato Y, Todo S: Macrophage migration inhibitory factor (MIF): Its potential role in tumor growth and tumor-associated angiogenesis. Ann $N Y$ Acad Sci 2003, 995: I7|- 182.

16. Shimizu T, Abe R, Nakamura H, Ohkawara A, Suzuki M, Nishihira J: High expression of macrophage migration inhibitory factor in human melanoma cells and its role in tumor cell growth and angiogenesis. Biochem Biophys Res Commun 1999, 264:751-758.

17. Takahashi N, Nishihira J, Sato Y, Kondo M, Ogawa H, Ohshima T, Une $Y$, Todo S: Involvement of macrophage migration inhibitory factor (MIF) in the mechanism of tumor cell growth. Mol Med 1998, 4:707-7|4.

18. Fingerle-Rowson G, Petrenko O, Metz CN, Forsthuber TG, Mitchell R, Huss R, Moll U, Muller W, Bucala R: The p53-dependent effects of macrophage migration inhibitory factor revealed by gene targeting. Proc Natl Acad Sci USA 2003, I 00:9354-9359.

19. Leng L, Metz CN, Fang YXJ, Donnelly S, Baugh J, Delohery T, Chen Y, Mitchell RA, Bucala R: MIF signal transduction initiated by binding to CD74. J Exp Med 2003, I97:|467-|476.

20. Lue H, Kapurniotu A, Fingerle-Rowson G, Roger T, Leng L, Thiele M, Calandra T, Bucala R, Bernhagen J: Rapid and transient activation of the ERK MAPK signalling pathway by macrophage migration inhibitory factor (MIF) and dependence on JAB I/CSN5 and Src kinase activity. Cell Signal 2006, I 8:688-703.

21. Lue H, Thiele M, Franz J, Dahl E, Speckgens S, Leng L, Fingerle-Rowson $G$, Bucala R, Luscher B, Bernhagen J: Macrophage migration inhibitory factor (MIF) promotes cell survival by activation of the Akt pathway and role for CSN5/JAB I in the control of autocrine MIF activity. Oncogene 2007, 26:5046-5059.

22. Mitchell RA, Liao H, Chesney J, Fingerle-Rowson G, Baugh J, David J, Bucala R: Macrophage migration inhibitory factor (MIF) sustains macrophage proinflammatory function by inhibiting p53: Regulatory role in the innate immune response. Proc Natl Acad Sci USA 2002, 99:345-350.

23. Nguyen $M$, Lue $H$, Kleemann R, Thiele M, Tolle G, Finkelmeier D, Wagner E, Braun A, Bernhagen J: The cytokine macrophage migration inhibitory factor (MIF) reduces pro-oxidative stress-induced apoptosis. J Immunol 2003, I 70:3337-3347.

24. Stein R, Mattes MJ, Cardillo TM, Hansen HJ, Chang $\mathrm{CH}$, Burton J, Govindan S, Goldenberg DM: CD74: a new candidate target for the immunotherapy of B-cell neoplasms. Clin Cancer Res 2007, I 3:5556s-5563s.

25. Meyer-Siegler KL, Iczkowski KA, Leng L, Bucala R, Vera PL: Inhibition of macrophage migration inhibitory factor or its receptor (CD74) attenuates growth and invasion of DU-I45 prostate cancer cells. J Immunol 2006, I 77:8730-8739.

26. Beswick EJ, Pinchuk IV, Suarez G, Sierra JC, Reyes VE: Helicobacter pylori CagA-dependent macrophage migration inhibitory factor produced by gastric epithelial cells binds to CD74 and stimulates procarcinogenic events. I Immunol 2006, I 76:6794-6801.

27. Shi X, Leng L, Wang T, Wang W, Du X, Li J, McDonald C, Chen Z, Murphy JW, Lolis E, Noble P, Knudson W, Bucala R: CD44 Is the Signaling Component of the Macrophage Migration Inhibitory Factor-CD74 Receptor Complex. Immunity 2006, 25:595-606. 
28. Gore $Y$, Starlets D, Maharshak N, Becker-Herman S, Kaneyuki U, Leng L, Bucala R, Shachar I: Macrophage migration inhibitory factor induces $B$ cell survival by activation of a CD74-CD44 receptor complex. J Biol Chem 2008, 283:2784-2792.

29. Abraham BK, Fritz P, McClellan M, Hauptvogel P, Athelogou M, Brauch $\mathrm{H}$ : Prevalence of CD44+/CD24-/low cells in breast cancer may not be associated with clinical outcome but may favor distant metastasis. Clin Cancer Res 2005, I I:I I54-I I59.

30. Diaz LK, Zhou X, Wright ET, Cristofanilli M, Smith T, Yang Y, Sneige $N$, Sahin A, Gilcrease MZ: CD44 expression is associated with increased survival in node-negative invasive breast carcinoma. Clin Cancer Res 2005, I I:3309-33 I4.

31. Xu X, Wang B, Ye C, Yao C, Lin Y, Huang X, Zhang Y, Wang S: Overexpression of macrophage migration inhibitory factor induces angiogenesis in human breast cancer. Cancer Lett 2008, 26 I: | 147-157.

32. Hagemann T, Wilson J, Kulbe H, Li NF, Leinster DA, Charles $\mathrm{K}$, Klemm F, Pukrop T, Binder C, Balkwill FR: Macrophages induce invasiveness of epithelial cancer cells via NF-kappa B and JNK. J Immunol 2005, I 75: I | 97- I 205.

33. Dahl E, Kristiansen G, Gottlob K, Klaman I, Ebner E, Hinzmann B, Hermann K, Pilarsky C, Durst M, Klinkhammer-Schalke M, Blaszyk H, Knuechel R, Hartmann A, Rosenthal A, Wild PJ: Molecular profiling of laser-microdissected matched tumor and normal breast tissue identifies karyopherin alpha2 as a potential novel prognostic marker in breast cancer. Clin Cancer Res 2006 , I 2:3950-3960

34. Noetzel E, Veeck J, Niederacher D, Galm O, Horn F, Hartmann A, Knuchel R, Dahl E: Promoter methylation-associated loss of ID4 expression is a marker of tumour recurrence in human breast cancer. BMC Cancer 2008, 8: 154 .

35. Remmele W, Stegner HE: [Recommendation for uniform definition of an immunoreactive score (IRS) for immunohistochemical estrogen receptor detection (ER-ICA) in breast cancer tissue]. Pathologe 1987, 8: I38-I40.

36. Gregory JL, Morand EF, McKeown SJ, Ralph JA, Hall P, Yang YH, McColl SR, Hickey MJ: Macrophage migration inhibitory factor induces macrophage recruitment via CC chemokine ligand 2. J Immunol 2006, I 77:8072-8079.

37. Ren Y, Tsui HT, Poon RT, Ng IO, Li Z, Chen Y, jiang G, Lau C, Yu WC, Bacher M, Fan ST: Macrophage migration inhibitory factor: roles in regulating tumor cell migration and expression of angiogenic factors in hepatocellular carcinoma. Int J Cancer 2003, 107:22-29.

38. Sobin $\mathrm{LH}$, Wittekind $\mathrm{CH}$ : TNM classification of malignant tumours. New York: Wiley; 1997.

39. Nemajerova A, Mena P, Fingerle-Rowson G, Moll UM, Petrenko O: Impaired DNA damage checkpoint response in MIF-deficient mice. EMBO J 2007, 26:987-997.

40. Coleman AM, Rendon BE, Zhao M, Qian MW, Bucala R, Xin D, Mitchell RA: Cooperative regulation of non-small cell lung carcinoma angiogenic potential by macrophage migration inhibitory factor and its homolog, D-dopachrome tautomerase. J Immunol 2008, I 8 I:2330-2337.

41. Weber C, Kraemer S, Drechsler M, Lue H, Koenen RR, Kapurniotu A, Zernecke A, Bernhagen J: Structural determinants of MIF functions in CXCR2-mediated inflammatory and atherogenic leukocyte recruitment. Proc Natl Acad Sci USA 2008, 105:16278-16283.

42. Meyer-Siegler KL, Leifheit EC, Vera PL: Inhibition of macrophage migration inhibitory factor decreases proliferation and cytokine expression in bladder cancer cells. BMC Cancer 2004, 4:34.

43. Flieger O, Engling A, Bucala R, Lue H, Nickel W, Bernhagen J: Regulated secretion of macrophage migration inhibitory factor is mediated by a non-classical pathway involving an $A B C$ transporter. FEBS Lett 2003, 55 I:78-86.

44. Mylona E, Giannopoulou I, Fasomytakis E, Nomikos A, Magkou C, Bakarakos $\mathrm{P}$, Nakopoulou L: The clinicopathologic and prognostic significance of CD44+/CD24(-/low) and CD44-/CD24+ tumor cells in invasive breast carcinomas. Hum Pathol 2008, 39:1096-1102

45. Kuo YC, Su CH, Liu CY, Chen TH, Chen CP, Wang HS: Transforming growth factor-beta induces CD44 cleavage that promotes migration of MDA-MB-435s cells through the up- regulation of membrane type I-matrix metalloproteinase. Int J Cancer 2009, 124:2568-2576.

46. Peng ST, Su CH, Kuo CC, Shaw CF, Wang HS: CD44 crosslinkingmediated matrix metalloproteinase- 9 relocation in breast tumor cells leads to enhanced metastasis. Int J Oncol 2007, 3I:III9-1I26.

47. Marangoni E, Lecomte N, Durand L, de Pinieux G, Decaudin D, Chomienne C, Smadja-joffe F, Poupon MF: CD44 targeting reduces tumour growth and prevents post-chemotherapy relapse of human breast cancers xenografts. Br J Cancer 2009 , 100:918-922.

48. Dewor M, Steffens G, Krohn R, Weber C, Baron J, Bernhagen J: Macrophage migration inhibitory factor (MIF) promotes fibroblast migration in scratch-wounded monolayers in vitro. FEBS Lett 2007, 58 I:4734-4742.

49. Ferrero-Pous M, Hacene K, Bouchet C, Le Doussal V, Tubiana-Hulin M, Spyratos F: Relationship between c-erbB-2 and other tumor characteristics in breast cancer prognosis. Clin Cancer Res 2000, 6:4745-4754.

50. Kouvaraki MA, Rassidakis GZ, Tian L, Kumar R, Kittas C, Claret FX Jun activation domain-binding protein I expression in breast cancer inversely correlates with the cell cycle inhibitor p27(Kip I). Cancer Res 2003, 63:2977-298I.

5I. Chauchereau A, Georgiakaki M, Perrin-Wolff M, Milgrom E, Loosfelt $\mathrm{H}$ : JAB I interacts with both the progesterone receptor and SRC-I. J Biol Chem 2000, 275:8540-8548.

52. Tomoda K, Kubota $Y$, Kato J-Y: Degradation of the cyclindependent-kinase inhibitor p27Kipl is instigated by Jabl. Nature 1999, 398:160-164.

53. Thiele M, Bernhagen J: Link between macrophage migration inhibitory factor (MIF) and cellular redox regulation. Antioxid Redox Signal 2005, 7: 1234-I 248.

54. Burnett GT, Weathersby DC, Taylor TE, Bremner TA: Regulation of inflammation- and angiogenesis-related gene expression in breast cancer cells and co-cultured macrophages. Anticancer Res 2008, 28:2093-2099.

\section{Pre-publication history}

The pre-publication history for this paper can be accessed here:

http://www.biomedcentral.com/1471-2407/9/230/pre pub

Publish with Bio Med Central and every scientist can read your work free of charge

"BioMed Central will be the most significant development for disseminating the results of biomedical research in our lifetime. "

Sir Paul Nurse, Cancer Research UK

Your research papers will be:

- available free of charge to the entire biomedical community

- peer reviewed and published immediately upon acceptance

- cited in PubMed and archived on PubMed Central

- yours - you keep the copyright 